\title{
Calcium-Stimulated Adenylyl Cyclases Modulate Ethanol- Induced Neurodegeneration in the Neonatal Brain
}

\author{
James W. Maas Jr, ${ }^{1}$ Ricardo A. Indacochea, ${ }^{1}$ Lisa M. Muglia, ${ }^{1}$ Timothy T. Tran, ${ }^{1}$ Sherri K. Vogt, ${ }^{1}$ Tim West, ${ }^{2}$ Ann Benz, ${ }^{3}$ \\ Amanda A. Shute, ${ }^{3}$ David M. Holtzman, ${ }^{2,4,5}$ Steven Mennerick, ${ }^{3}$ John W. Olney, ${ }^{3}$ and Louis J. Muglia ${ }^{1,4}$ \\ Departments of ${ }^{1}$ Pediatrics, ${ }^{2}$ Neurology, ${ }^{3}$ Psychiatry, and ${ }^{4}$ Molecular Biology and Pharmacology and ${ }^{5}$ Hope Center for Neurological Disorders, Washington \\ University School of Medicine, St. Louis, Missouri 63110
}

Fetal alcohol exposure results in cognitive and neurobehavioral deficits, but the effects of modifying genetic loci on the severity of these sequelas have not been well characterized. Although the cAMP signaling pathway has been shown to be an important modulator of ethanol sensitivity in adult mice, its potential role in modulating ethanol-induced neurodegeneration has not been examined. Adenylyl cyclases (ACs) 1 and 8 produce cAMP in response to intracellular calcium elevation and modulate several aspects of neuronal function, including ethanol sensitivity. $\mathrm{AC} 1$ and $\mathrm{AC} 8$ are expressed widely throughout the brain of neonatal mice, and genetic deletion of both AC1 and AC8 in double-knock-out (DKO) mice enhances ethanol-induced neurodegeneration in the brains of neonatal mice. In addition, ethanol treatment induces significantly greater levels of caspase-3 activation in the brains of DKO mice compared with wild-type (WT) mice, reflecting higher numbers of apoptotic neurons. Administration of the NMDA receptor antagonist MK801 [(+)-5-methyl-10,11dihydro-5H-dibenzo [a,d] cyclohepten-5,10-imine hydrogen maleate] or the $\mathrm{GABA}_{\mathrm{A}}$ receptor potentiator phenobarbital, which mimics components of the effects of ethanol on neurons, results in significantly greater neurodegeneration in the brains of neonatal DKO mice than WT mice. Furthermore, loss of a single calcium-stimulated AC isoform potentiates neurodegeneration after administration of ethanol, MK801, or phenobarbital. In contrast, the levels of physiological cell death, death after hypoxia/ischemia, and excitotoxic cell death are not increased in the brains of DKO mice. Thus, $\mathrm{AC} 1$ and $\mathrm{AC} 8$ are critical modulators of neurodegeneration induced by activity blockade in the neonatal brain and represent genetic loci that may potentially modify the severity of fetal alcohol syndrome.

Key words: adenylyl cyclase; calcium; cAMP; ethanol; knock-out mouse; pharmacology

\section{Introduction}

Fetal alcohol syndrome (FAS) results from in utero exposure of the human fetus to ethanol that leads to severe developmental abnormalities in children that extend into adulthood, including cognitive dysfunction, neurobehavioral disruption, and growth deficits (Jones and Smith, 1973; Streissguth et al., 1991). The incidence of fetal alcohol spectrum disorders has been estimated to be as high as 9.1 in 1000 live births (Sampson et al., 1997). Despite the widespread prevalence of FAS, the modifying influences, including fetal genotype, that determine the likelihood of developing cognitive sequelas after fetal ethanol exposure are not well understood. Recently, it was discovered that acute exposure of neonatal rodents to ethanol leads to widespread neurodegeneration in the CNS (Ikonomidou et al., 2000). This neurodegeneration likely results from the antagonism of NMDA receptors and potentiation of $\mathrm{GABA}_{\mathrm{A}}$ receptors by ethanol, because agents that mimic these components of the effects of ethanol on neuronal function also result in widespread neuronal death when administered to neonatal rodents (Ikonomidou et al., 2000). These

Received Dec. 3, 2004; revised Jan. 15, 2005; accepted Jan. 17, 2005.

This work was supported by National Institutes of Health Grants AA12957 and AG18876 (to L.J.M.) and AA12952 (to S.M.). J.W.M. thanks the Washington University Medical Scientist Training Program for financial support.

Correspondence should be addressed to Dr. Louis J. Muglia, 660 South Euclid Avenue, Campus Box 8208, St. Louis, M0 63110. E-mail: muglia_@@ids.wustl.edu.

DOI:10.1523/JNEUROSCI.4940-04.2005

Copyright $\odot 2005$ Society for Neuroscience $\quad$ 0270-6474/05/252376-10\$15.00/0 effects of ethanol are limited to a narrow developmental window that coincides with a time of widespread synaptogenesis. It is likely that the cognitive and neurobehavioral deficits in FAS are attributable to neurodegeneration resulting from ethanol exposure during this period of synaptogenesis.

Unfortunately, the mechanisms that underlie or modulate this ethanol-mediated neurodegeneration are not well understood. It is likely that the neurodegeneration results from the inhibition of processes by ethanol that are important for activitydependent survival in developing neurons (Franklin and Johnson, 1992; Verhage et al., 2000). The activity-dependent survival of a wide variety of neurons from the CNS depends on depolarization-induced elevation of intracellular calcium and the subsequent activation of multiple signaling cascades (Mennerick and Zorumski, 2000). The cAMP signal transduction system has also been shown to be important for the survival of multiple CNS neuron populations (D’Mello et al., 1993; Meyer-Franke et al., 1995, 1998; Hanson et al., 1998; Reiriz et al., 2002; Lara et al., 2003). Adenylyl cyclases (ACs), which convert ATP to cAMP, are crucial components of the cAMP signal transduction pathway; furthermore, two $\mathrm{AC}$ isoforms, $\mathrm{AC} 1$ and $\mathrm{AC}$, are directly stimulated by calcium and thus are potential loci of interaction between the cAMP and calcium signal transduction pathways (Tang et al., 1991; Cali et al., 1994; Wu et al., 1995; Wong et al., 1999; Schaefer et al., 2000).

In addition to its role in the regulation of neuronal survival, 
recent evidence has implicated the cAMP signal transduction system as an important modulator of ethanol sensitivity in adult animals; genetic manipulations that decrease the activity of this pathway result in increased sensitivity to the sedative effects of ethanol (Moore et al., 1998; Thiele et al., 1998; Wand et al., 2001). Among these are mice with genetic deletions of AC1 and/or AC8, which display enhanced sensitivity to the sedative effects of ethanol, altered voluntary ethanol consumption, and altered cAMPdependent signal transduction in response to ethanol administration (J. W. Maas and L. J. Muglia, unpublished results). Based on this information, we hypothesized that neonatal mice with genetic deletions of $\mathrm{AC} 1$ and $\mathrm{AC} 8$ would demonstrate increased sensitivity to ethanol-induced neurodegeneration. We report here that neonatal mice with genetic deletion of AC1 and AC8 display enhanced neurodegeneration after administration of ethanol, as well as after administration of an NMDA receptor antagonist or a $\mathrm{GABA}_{\mathrm{A}}$ receptor modulator, demonstrating that the calcium-stimulated ACs are important modulators of neurodegeneration induced by activity blockade.

\section{Materials and Methods}

Animal husbandry. All mice were backcrossed at least nine generations to C57BL/ 6 mice from The Jackson Laboratory (Bar Harbor, ME). To generate mice for these experiments, we used progeny of homozygous mutants and C57BL/6 mice from The Jackson Laboratory bred in our colony. Mice were maintained on a $12 \mathrm{~h}$ light/dark cycle with ad libitum access to food and water, except as indicated. All experiments were performed using male mice at $7 \mathrm{~d}$ after birth [postnatal day 7 (P7)]. All mouse protocols were in accordance with the National Institutes of Health guidelines and were approved by the Animal Care and Use Committee of Washington University School of Medicine.

In situ hybridization. Paraformaldehyde-fixed brains from male P7 mice were cut into $10 \mu \mathrm{m}$ coronal and sagittal sections and hybridized with probes specific for $\mathrm{AC} 1$ and $\mathrm{AC} 8$ as described previously (Schaefer et al., 2000).

Drug treatment. P7 neonatal mice were injected subcutaneously with drugs and returned to their home cage. Drug treatments were as follows: 2.2 or $2.5 \mathrm{~g} / \mathrm{kg}$ ethanol $(20 \% \mathrm{w} / \mathrm{v}$ in $0.9 \% \mathrm{NaCl})$ at 0 and $2 \mathrm{~h}, 70 \mathrm{mg} / \mathrm{kg}$ phenobarbital $(7 \mathrm{mg} / \mathrm{ml}$ in $0.9 \% \mathrm{NaCl}$; Elkins-Sinn, Cherry Hill, NJ) at $0 \mathrm{~h}$, or $0.65 \mathrm{mg} / \mathrm{kg}$ MK801 [(+)-5-methyl-10,11-dihydro-5H-dibenzo [a,d] cyclohepten-5,10-imine hydrogen maleate] $(65 \mu \mathrm{g} / \mathrm{ml}$ in $0.9 \%$ $\mathrm{NaCl}$; Sigma, St. Louis, $\mathrm{MO}$ ) at 0, 6, and $12 \mathrm{~h}$. Ethanol administration in this paradigm results in a binge-like episode of ethanol exposure that has been well validated to cause neurodegeneration without nonneurological sequelas. We, among others, have extensively characterized the neurodegeneration induced by ethanol administration in neonatal mice (Wozniak et al., 2004).

Silver staining. Mice were anesthetized and transcardially perfused with $4 \%$ paraformaldehyde $24 \mathrm{~h}$ after the first injection. After perfusion, the brain was removed and postfixed for $2 \mathrm{~d}$ in paraformaldehyde in cacodylate buffer before it was cut into $50 \mu \mathrm{m}$ sections using a vibratome. Floating sections were washed in distilled $\mathrm{H}_{2} \mathrm{O}$ and stained using the procedure of DeOlmos and Ingram (1971). This well validated technique results in the deposition of a black precipitate in degenerating neurons and neuronal processes and reflects the integration of neuronal degeneration over a $24 \mathrm{~h}$ time period (Olney et al., 2002; Wozniak et al., 2004).

Quantitation of neurodegeneration. To efficiently assess the degree of neurodegeneration induced by each of the drug treatments, we developed a semiquantitative scoring system to quantify the degree and extent of silver deposition in each brain region. Each region was assessed by at least two independent observers blinded to genotype and assigned a score between 0 and 4 (in increments of 0.5 ) that reflected the degree of silver deposition in that region. In all cases, scores were determined by comparing the degree of silver deposition to a set of representative sections that corresponded to the range of neurodegeneration scores for that region. The neurodegeneration scores were highly correlated between independent observers.
Western blot analysis. Mice were injected with $2.2 \mathrm{~g} / \mathrm{kg}$ ethanol at 0 and $2 \mathrm{~h}$. At various times after injections, mice were killed by $\mathrm{CO}_{2}$ inhalation, and the brains were removed and snap frozen in liquid nitrogen. Brains were homogenized in cold lysis buffer containing $150 \mathrm{~mm} \mathrm{NaCl}, 2 \mathrm{~mm}$ EDTA, 1\% Triton X-100, 10\% glycerol, and $20 \mathrm{~mm}$ Tris, pH 7.5. Sigma protease inhibitor mixture and phosphatase inhibitor mixtures 1 and 2 (Sigma) were added to the lysis buffer before homogenization. After homogenization, lysates were centrifuged at $10,000 \times g$, and the supernatant was collected and stored at $-80^{\circ} \mathrm{C}$. Protein concentrations were determined by the BCA assay (Pierce, Rockford, IL). Equal amounts of protein were subjected to SDS-PAGE and transferred to a nitrocellulose membrane. Membranes were probed with anticleaved caspase- 3 primary antibody (Cell Signaling Technology, Beverly, MA) at a dilution of 1:1000. Primary antibody was detected using HRP-conjugated goat antirabbit secondary antibody, and signals were visualized using chemiluminescence (SuperSignal West Dura kit; Pierce). Densitometric analysis was performed using Un-Scan-It (Silk Scientific, Orem, UT).

Plasma ethanol concentration determination. Mice were injected with $2.2 \mathrm{~g} / \mathrm{kg}$ ethanol at 0 and $2 \mathrm{~h}$. At various times after injection, mice were decapitated, and blood was collected using heparinized microhematocrit capillary tubes. Blood was centrifuged at $10,000 \times g$ for $2 \mathrm{~min}$ at $4^{\circ} \mathrm{C}$, and the plasma was collected and stored at $-80^{\circ} \mathrm{C}$ until analysis. Plasma ethanol concentrations were determined using an ethanol diagnostic kit (Pointe Scientific, Lincoln Park, MI).

Hypoxia/ischemia and Asp-Glu-Val-Asp-aminomethylcoumarin assay. P7 pups were subjected to the modified Levine procedure (Levine, 1960; Han et al., 2000). Briefly, pups were weighed and anesthetized with 5\% halothane for induction and $1.5 \%$ halothane for maintenance, and the left carotid artery was exposed and cauterized. The incision was sutured, and the pups were returned to the dam for a $2 \mathrm{~h}$ recovery period, after which they were put in chambers maintained at $37^{\circ} \mathrm{C}$ through which $8 \%$ humidified oxygen (balance nitrogen) flowed for $45 \mathrm{~min}$. After completion of the hypoxia/ischemia (H/I) injury, pups were returned to the dam until killing $24 \mathrm{~h}$ after H/I. After the animals were killed, the brain was removed, and the left and right hippocampi were dissected on ice and then frozen on dry ice. Each hippocampus was homogenized in $70 \mu \mathrm{l}$ of lysis buffer $\left(20 \mathrm{~mm}\right.$ HEPES, pH 7.4, $7.5 \mathrm{~mm} \mathrm{MgCl}_{2}, 1 \mathrm{~mm}$ $\beta$-mercaptoethanol, $1 \%$ Triton X-100, 2 mm EGTA, and $230 \mathrm{~mm} \mathrm{su}-$ crose) with protease inhibitors (Roche Diagnostics, Indianapolis, IN) and centrifuged at $14,000 \mathrm{rpm}$ for $15 \mathrm{~min}$ at $4^{\circ} \mathrm{C}$. Tissue lysates $(10 \mu \mathrm{l})$ were incubated in an opaque 96-well plate with $90 \mu \mathrm{l}$ of assay buffer (10 mM HEPES, pH 7.4, $42 \mathrm{~mm} \mathrm{KCl,} 5 \mathrm{~mm} \mathrm{MgCl}_{2}, 1 \mathrm{~mm}$ DTT, and $10 \%$ sucrose) containing $30 \quad \mu \mathrm{M}$ acetyl-Asp-Glu-Val-Asp (DEVD)aminomethylcoumarin (AMC) (Calbiochem, San Diego, CA). The emitted fluorescence was measured every $5 \mathrm{~min}$ for $30 \mathrm{~min}$ at an excitation wavelength of $360 \mathrm{~nm}$ and an emission wavelength of $460 \mathrm{~nm}$ using a microplate fluorescence reader (Bio-Tek Instruments, Winooski, VT). The protein concentration of each lysate was determined by BCA assay (Pierce). Acetyl-AMC (Calbiochem) was used to obtain a standard curve, and the enzyme activity was calculated as picomoles of AMC generated per milligram of protein per minute.

Excitotoxicity. Induction of excitotoxic neuron death was performed as described previously, using $1.25 \mathrm{~g} / \mathrm{kg}$ monosodium glutamate (Sigma) (Olney, 1971). Sections containing the maximal extent of the median eminence were identified, and the number of degenerating neurons and the area of degeneration were quantified.

Hippocampal cultures. Cultures were prepared as described previously (Moulder et al., 2002). Briefly, hippocampi were harvested from P0 and P1 mouse pups and digested with papain and mechanically dispersed. Cells were seeded at a density of $1500 / \mathrm{mm}^{2}$ onto $35 \mathrm{~mm}$ dishes precoated with collagen $(0.5 \mathrm{mg} / \mathrm{ml}$; Sigma). Cultures were treated with drugs or saline, as indicated, from day 4 in vitro (DIV4) to DIV10. Drugs included ethanol or tetrodotoxin (Sigma). For ethanol treatment, cultures were also maintained in a humidified chamber containing $50 \mathrm{~mm}$ ethanol to prevent evaporation of ethanol from the dish. Survival was assessed on DIV10 by counting remaining cells with smooth, phase-bright appearance to their soma and visible processes. In all cases, survival was normalized to control cultures plated at the same time as the experimental cultures. 
A
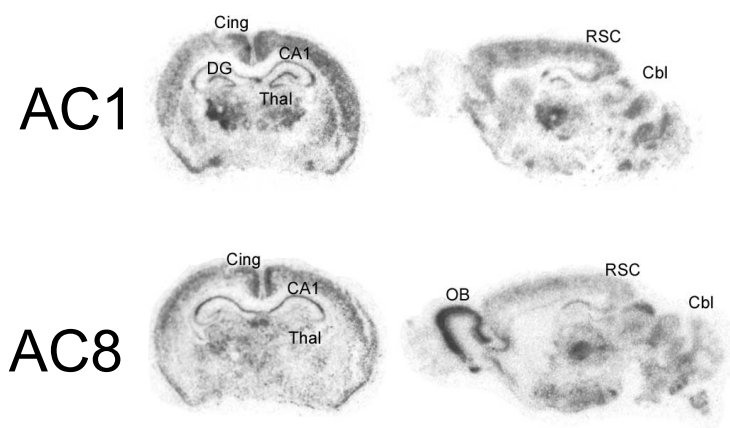

B

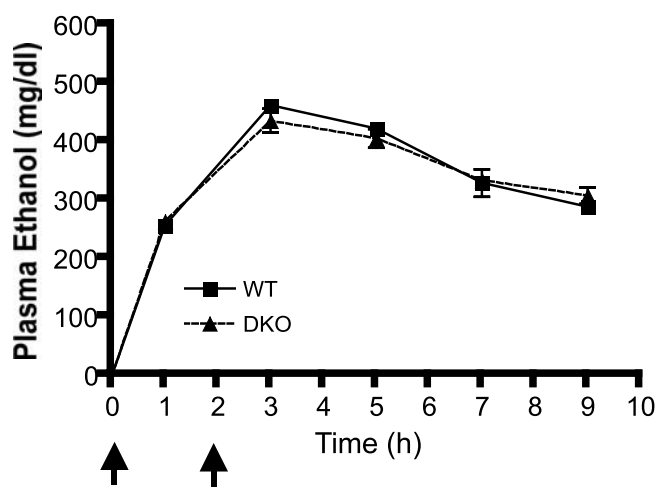

Figure 1. $A C 1$ and $A C 8$ are expressed widely in the brain at $P 7$ and do not modulate ethanol metabolism. $\boldsymbol{A}$, In situ hybridization for mRNAs for AC1 and AC8 in coronal (left) and sagittal (right) brain sections at P7. AC1 and $A C 8$ are both present in cingulate cortex (Cing), parietal cortex, retrosplenial cortex (RSC), cerebellum (Cbl), area CA1 of the hippocampus (CA1), and thalamus (Thal). In addition, $A C 1$ is present in dentate gyrus (DG), and $A C 8$ is present in olfactory bulb (OB). $\boldsymbol{B}$, Plasma ethanol concentration at various times after ethanol administration in $\mathrm{P7}$ mice. We administered $2.2 \mathrm{~g} / \mathrm{kg}$ ethanol subcutaneously at 0 and $2 \mathrm{~h}$ (indicated by arrows). $n=$ 5 mice for all points except $t=3 \mathrm{~h}$, where $n=14$ mice.

Statistical analysis. Mann-Whitney $t$ tests and one-way and two-way ANOVA tests, followed by Bonferonni post hoc tests when appropriate, were performed to evaluate statistical significance. $F$ statistics and $p$ values are indicated in the text and figure legends.

\section{Results}

AC1 and AC8 are distributed widely throughout the neonatal mouse brain

Although the distribution of the calcium-stimulated ACs in the adult brain has been established (Xia et al., 1991; Muglia et al., 1999), their expression in the neonatal brain has not been well characterized. We examined the distribution of the mRNAs for $\mathrm{AC} 1$ and $\mathrm{AC} 8$ by in situ hybridization (Fig. 1A). AC1 and AC8 were widely expressed throughout the brain at P7; both isoforms were expressed in cingulate, parietal, and retrosplenial cortices, area CA1 of the hippocampus, cerebellum, and thalamus. In addition, AC1 is expressed in the dentate gyrus, whereas AC8 is expressed in the olfactory bulb and hypothalamus.

\section{Loss of AC1 and AC8 does not alter ethanol metabolism}

We hypothesized that the calcium-stimulated ACs would be important modulators of the neurotoxic effects of ethanol in the developing brain. Before we addressed this question, we assessed whether deletion of the calcium-stimulated ACs would alter ethanol metabolism. As seen in Figure $1 B$, plasma ethanol concentrations at various times after administration of $2.2 \mathrm{~g} / \mathrm{kg}$ ethanol (at 0 and $2 \mathrm{~h}$ ) did not differ between wild-type (WT) and double- knock-out (DKO) mice with genetic deletions of both AC1 and $\mathrm{AC} 8$, indicating that $\mathrm{AC} 1$ and $\mathrm{AC} 8$ do not modulate ethanol metabolism.

\section{Neurodegeneration after ethanol exposure is enhanced in the brains of DKO mice}

Several studies have indicated that $\mathrm{AC} 1$ and $\mathrm{AC} 8$ perform redundant functions in some instances, such that the loss of one isoform can be compensated for by the remaining isoform (e.g., AC8 in AC1 KO mice and vice versa) (Wong et al., 1999). If this were the case for the modulation of ethanol-induced neurodegeneration, examining mice with genetic deletion of either AC1 or AC8 alone might lead to an erroneous conclusion about the role played by the calcium-stimulated ACs. To avoid this possibility, we began our studies by examining ethanol-induced neurodegeneration in DKO mice, because they have no residual calciumstimulated AC activity in the brain (Wong et al., 1999). We assessed the degree of neuronal death in the brains of neonatal WT and DKO mice $24 \mathrm{~h}$ after administration of $2.2 \mathrm{~g} / \mathrm{kg}$ ethanol at 0 and $2 \mathrm{~h}$ using the cupric-silver method for impregnation of degenerating neurons and neuronal processes described by DeOlmos and Ingram (1971). We quantified the extent and degree of neurodegeneration, as indicated by silver deposition, in multiple brain regions of WT and DKO mice (Fig. $2 A-C$ ). Representative sections corresponding to the median amount of silver deposition for each genotype in the anterodorsal and anteroventral nuclei of the thalamus (Fig. 2A), hippocampus, cingulate cortex, and parietal cortex (Fig. $2 B$ ), and subiculum and retrosplenial cortex (Fig. 2C) demonstrate a greater amount of neurodegeneration in multiple brain regions of DKO mice compared with WT mice. Quantification of sections from multiple animals demonstrates that administration of $2.2 \mathrm{~g} / \mathrm{kg}$ ethanol induces significantly greater neurodegeneration in the hippocampus, cingulate, parietal, and retrosplenial cortices, and subiculum of DKO mice compared with WT mice $\left(F_{(1,115)}=80.14 ; p<0.0001\right)$ (Fig. $\left.2 D\right)$. A similar result was found $24 \mathrm{~h}$ after administration of $2.5 \mathrm{~g} / \mathrm{kg}$ ethanol at 0 and $2 \mathrm{~h}$, with the brains of DKO mice demonstrating significantly greater levels of degeneration than WT brains, specifically in the anterodorsal and anteroventral nuclei of the thalamus, the hippocampus, and the parietal cortex $\left(F_{(1,104)}=40.29\right.$; $p<0.0001$ ) (Fig. $2 E$ ). In contrast, no significant neurodegeneration was detected in the brain of either WT or DKO mice $24 \mathrm{~h}$ after administration of $2.0 \mathrm{~g} / \mathrm{kg}$ ethanol at 0 and $2 \mathrm{~h}$ (data not shown).

\section{DKO neurons have enhanced sensitivity to ethanol-induced death in vitro}

It is possible that the enhanced sensitivity of DKO neurons to ethanol-induced death is not caused by intrinsic changes in the function of AC-expressing neurons but rather is attributable to secondary modifications in neuronal interactions with other cell types. To evaluate whether increased ethanol sensitivity is likely a direct effect of ethanol on neuronal function, we used an in vitro model of ethanol neurodegeneration. Survival of primary hippocampal neurons in postnatal cultures is severely compromised by ethanol exposure during the period of development and synaptogenesis that is thought to correlate with in vivo developmental processes (Moulder et al., 2002). We isolated hippocampal neurons from WT and DKO mice and grew them in the presence of $50 \mathrm{~mm}$ ethanol. Under these conditions, $36.6 \pm 3.6 \%$ of WT neurons and $60.0 \pm 8.0 \%$ of DKO neurons died after $6 \mathrm{~d}$ of treatment $(p<0.05)$ (Fig. $2 F)$. In contrast, treatment with $1 \mu \mathrm{M}$ 
A

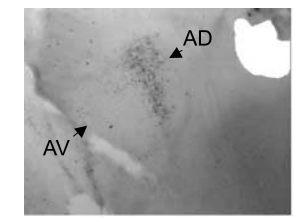

WT

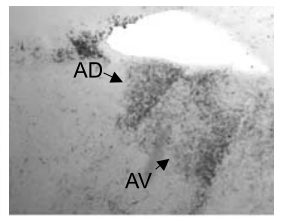

DKO

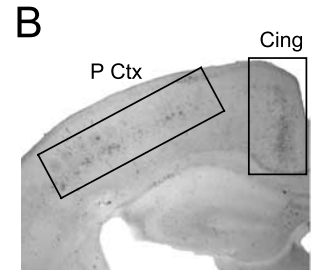

WT

C

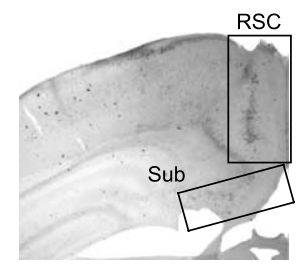

WT

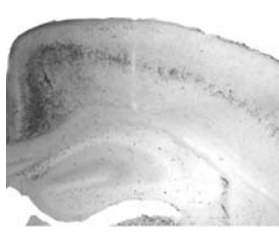

DKO

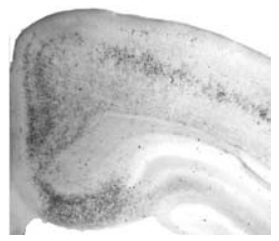

DKO
D

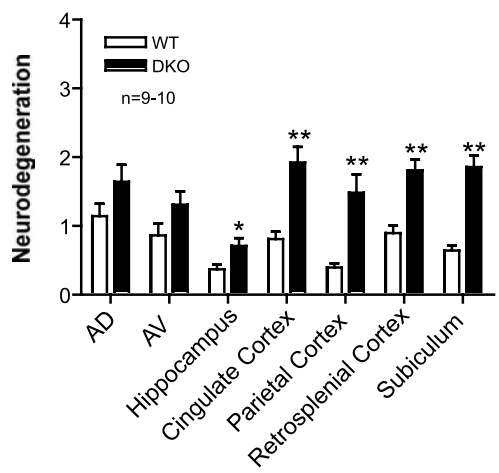

E
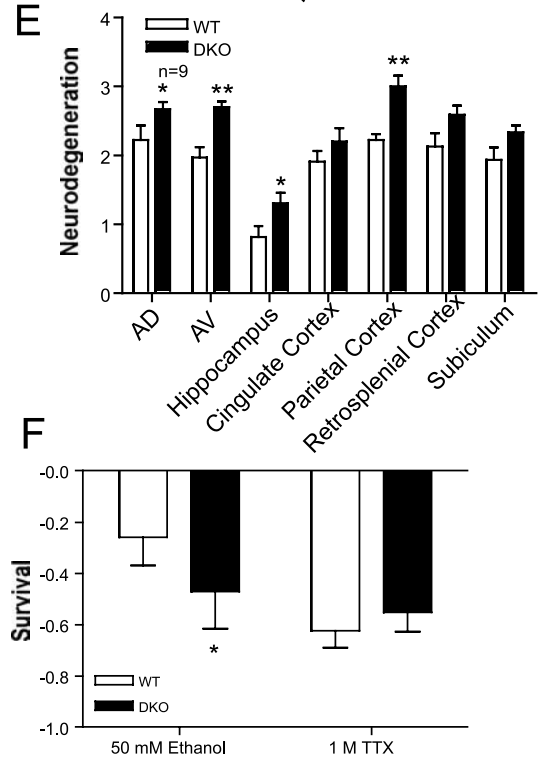

Figure 2. Ethanol-induced neurodegeneration is enhanced in the brains of neonatal DKO mice. $A$, Representative sections depicting the median amount of silver deposition for each genotype in the anterodorsal (AD) and anteroventral (AV) thalamic nuclei of WT and DKO brains $24 \mathrm{~h}$ after administration of two doses of $2.2 \mathrm{~g} / \mathrm{kg}$ ethanol. $\boldsymbol{B}$, Representative sections depicting the median amount of silver deposition for each genotype in the hippocampus, cingulate cortex (Cing), and parietal cortex ( $\mathrm{P}(\mathrm{tx})$ of WT and DKO brains $24 \mathrm{~h}$ after administration of two doses of $2.2 \mathrm{~g} / \mathrm{kg}$ ethanol. C, Representative sections depicting the median amount of silver deposition for each genotype in the retrosplenial cortex (RSC) and subiculum (Sub) of WT and DKO brains $24 \mathrm{~h}$ after administration of two doses of $2.2 \mathrm{~g} / \mathrm{kg}$ ethanol. $\boldsymbol{D}$, Quantitation of neurodegeneration in various brain regions of neonatal WT and DKO mice $24 \mathrm{~h}$ after administration of two doses of $2.2 \mathrm{~g} / \mathrm{kg}$ ethanol $\left({ }^{*} p<0.05 \mathrm{vs} \mathrm{WT;}{ }^{* *} p<0.01 \mathrm{vs} \mathrm{WT;} n=9-10\right.$ mice per genotype). $\boldsymbol{E}$, Quantitation of neurodegeneration in various brain regions of neonatal WT and DKO mice $24 \mathrm{~h}$ after administration of two doses of $2.5 \mathrm{~g} / \mathrm{kg}$ ethanol ( ${ }^{*} p<0.05$ vs WT; ${ }^{* *} p<0.01$ vs WT; $n=9$ mice per genotype). $\boldsymbol{F}$, Survival of hippocampal neurons from WT and DKO mice cultured in the presence of $50 \mathrm{~mm}$ ethanol or $1 \mu \mathrm{m}$ tetrodotoxin (TTX) $\left({ }^{*} p<0.05\right.$ vs WT; $n=5-6$ per genotype).

tetrodotoxin resulted in equivalent levels of death of WT and DKO neurons $(62.3 \pm 6.6$ vs $55.3 \pm 7.5 \%)$ (Fig. $2 F)$.

\section{Ethanol administration induces a greater degree of caspase-3} activation in the brains of DKO mice than WT mice

The neurodegeneration induced by neonatal ethanol exposure has been demonstrated previously to be apoptotic in nature (Ikonomidou et al., 2000; Olney et al., 2002; Young et al., 2003). In particular, it has been shown that this process results in the activation of caspase- 3 and that blocking the activation of caspase-3 prevents ethanol-induced neurodegeneration (Olney et al., 2002; Young et al., 2003). We assessed the degree of caspase- 3 activation in the brains of WT and DKO mice after ethanol administration by Western blot analysis using an antibody that detects the cleaved form of caspase-3, which is the active form of the molecule (Boatright and Salvesen, 2003).
Caspase- 3 activation was induced in the brain of WT mice within $4 \mathrm{~h}$ of ethanol administration, peaked at 8 and $12 \mathrm{~h}$, and was absent by $24 \mathrm{~h}$ after ethanol administration (Fig. 3A). A similar temporal profile of caspase- 3 activation was seen in the brain of DKO mice (Fig. 3A). Direct comparison of the levels of cleaved caspase-3 between WT and DKO mice demonstrated that caspase- 3 activation was significantly greater in the brains of $\mathrm{DKO}$ mice at both $8 \mathrm{~h}$ (Fig. $3 \mathrm{~B}, \mathrm{C}$ ) and $12 \mathrm{~h} \mathrm{(Fig.}$ 3D) after ethanol exposure. Cleaved caspase- 3 levels were threefold and twofold higher at 8 and $12 \mathrm{~h}$, respectively, in the brains of DKO mice compared with WT mice (Fig. $3 C, D$ ), reflecting a greater degree of apoptotic neurodegeneration in the brains of DKO mice after ethanol administration.

\section{Phenobarbital-induced neurodegeneration is enhanced in the brains of DKO mice}

Ethanol acts as an antagonist of the NMDA receptor and potentiator of the $\mathrm{GABA}_{\mathrm{A}}$ receptor, and it is has been demonstrated previously that administration of agents that mimic these components of the actions of ethanol are sufficient to induce neurodegeneration (Ikonomidou et al., 2000). We examined the degree of neurodegeneration induced in the brains of WT and DKO mice $24 \mathrm{~h}$ after administration of $70 \mathrm{mg} / \mathrm{kg}$ phenobarbital, a modulator of the $\mathrm{GABA}_{\mathrm{A}}$ receptor. Representative sections that depict the median amount of silver deposition for each genotype in anterodorsal and anteroventral thalamic nuclei (Fig. 4A), hippocampus, cingulate, and parietal cortices (Fig. 4B), and retrosplenial cortex and subiculum (Fig. $4 C$ ) demonstrate that phenobarbital treatment induced greater neurodegeneration in multiple regions of the DKO brain. Quantitation of sections from multiple animals demonstrates that phenobarbital-induced neurodegeneration was significantly enhanced in all brain regions examined in DKO mice compared with WT mice $\left(F_{(1,82)}=117.6\right.$; $p<0.0001$ ) (Fig. 4D).

\section{MK801-induced neurodegeneration is enhanced in the brains of DKO mice}

In a parallel set of experiments, we examined the degree of neurodegeneration induced in the brains of WT and DKO mice $24 \mathrm{~h}$ after administration of the NMDA receptor antagonist MK801 $(0.65 \mathrm{mg} / \mathrm{kg}$ at 0,6 , and $12 \mathrm{~h})$. Although this dose is higher than that which produces behavioral alterations in adult mice, it is similar to that used previously to produce neurodegeneration in neonatal rodents (Ikonomidou et al., 1999, 2000). Figure 5 depicts representative sections reflecting the median amount of neurodegeneration for each genotype in several regions of the brains of WT and DKO mice, including anterodorsal and antero- 
ventral thalamic nuclei (Fig. 5A), hippocampus, cingulate, and parietal cortices (Fig. $5 B$ ), and retrosplenial cortex and subiculum (Fig. 5C). As shown in Figure 5D, MK801 treatment resulted in significantly greater neurodegeneration in the anterodorsal and anteroventral thalamic nuclei and cingulate, parietal, and retrosplenial cortices of DKO mice compared with WT mice $\left(F_{(1,70)}=\right.$ 114.4; $p<0.0001$ ).

Loss of a single calcium-stimulated AC isoform is sufficient to potentiate neurodegeneration after administration of ethanol

It is possible that the enhanced neurodegeneration seen in the brains of DKO mice after administration of ethanol may in fact be attributable solely to the loss of a single calcium-stimulated AC isoform. Conversely, it may be the case that loss of a single calcium-stimulated AC isoform may be compensated for by the remaining isoform (i.e., $\mathrm{AC} 1$ in $\mathrm{AC} 8 \mathrm{KOs}$ and vice versa), such that neurodegeneration in the brains of $\mathrm{AC} 1 \mathrm{KO}$ and $\mathrm{AC} 8 \mathrm{KO}$ mice after administration of ethanol will not differ from that seen in the brains of WT mice. To address these possibilities, we assessed neurodegeneration in the brains of $\mathrm{ACl}$ $\mathrm{KO}$ and $\mathrm{AC} 8 \mathrm{KO}$ mice $24 \mathrm{~h}$ after administration of $2.2 \mathrm{~g} / \mathrm{kg}$ ethanol at 0 and $2 \mathrm{~h}$. As seen in Figure 6A, ethanol-induced neurodegeneration was significantly greater than that seen in WT brain in the anterodorsal nucleus of the thalamus and cingulate, parietal, and retrosplenial cortices in the brains of both $\mathrm{AC} 1 \mathrm{KO}\left(F_{(1,91)}=\right.$ $41.78 ; p<0.0001)$ and $\mathrm{AC} 8 \mathrm{KO}\left(F_{(1,91)}=\right.$ 76.92; $p<0.0001)$ mice. Furthermore, the degree of neurodegeneration seen in AC1 $\mathrm{KO}$ and $\mathrm{AC} 8 \mathrm{KO}$ mice did not differ from that seen in DKO mice. Twenty-four hours after administration of $2.5 \mathrm{~g} / \mathrm{kg}$ ethanol at 0 and $2 \mathrm{~h}$, the brains of $\mathrm{AC} 1 \mathrm{KO}\left(F_{(1,81)}=21.13\right.$; $p<$ $0.0001)$ and $\mathrm{AC} 8 \mathrm{KO}\left(F_{(1,81)}=9.938 ; p<0.005\right)$ mice demonstrated significantly enhanced neurodegeneration compared with WT mice, particularly in the anterodorsal thalamic nucleus (AC8 $\mathrm{KO})$ and cingulate cortex and subiculum (AC1 KO) (Fig. 6B).

\section{Loss of a single calcium-stimulated AC isoform is sufficient to potentiate neurodegeneration after administration of phenobarbital and MK801}

It is possible that $\mathrm{AC} 1$ and $\mathrm{AC} 8$ may modulate sensitivity to different components of ethanol-induced neurodegeneration, such that $\mathrm{AC} 1$ modulates neurodegeneration induced by the antagonism of ethanol of the NMDA receptor and AC8 that which is induced by the potentiation of ethanol of the $\mathrm{GABA}_{\mathrm{A}}$ receptor (or vice versa). To assess these possibilities, we treated $\mathrm{AC} 1 \mathrm{KO}$ and $\mathrm{AC} 8$ KO mice with phenobarbital $(70 \mathrm{mg} / \mathrm{kg})$ or MK801 $(0.65 \mathrm{mg} / \mathrm{kg}$ at 0 , 6 , and $12 \mathrm{~h}$ ) and measured neurodegeneration $24 \mathrm{~h}$ later. Phenobarbital-induced neurodegeneration was significantly enhanced in the brains of $\mathrm{ACl} \mathrm{KO}\left(F_{(1,73)}=35.64 ; p<0.0001\right)$ and
AC8 KO $\left(F_{(1,73)}=58.69 ; p<0.0001\right)$ mice compared with WT mice, particularly in the anterodorsal thalamic nucleus (AC1 $\mathrm{KO})$ and cingulate and parietal cortices ( $\mathrm{ACl} \mathrm{KO}$ and $\mathrm{AC} 8 \mathrm{KO}$ ) (Fig. 6C). MK801-induced neurodegeneration was also significantly enhanced in the brains of AC1 $\mathrm{KO}\left(F_{(1,70)}=7.529 ; p<\right.$ $0.01)$ and $\operatorname{AC} 8 \mathrm{KO}\left(F_{(1,66)}=74.05 ; p<0.0001\right)$ mice, particularly in the parietal cortex (AC8 KO) (Fig. 6D).

\section{Loss of calcium-stimulated ACs does not potentiate other forms of neuronal death}

Although we have shown that AC1 and AC8 are important modulators of neurodegeneration after activity blockade, it is possible that these ACs may in fact modulate neuronal death after any insult to the developing brain. To assess this possibility, we examined neurodegeneration in neonatal WT and DKO mice in two different paradigms: excitotoxic neuronal death after administration of monosodium glutamate and apoptotic death of hippocampal neurons $24 \mathrm{~h}$ after H/I induced by unilateral carotid artery ligation and transient exposure to hypoxic conditions. We assessed the extent of excitotoxic cell death in the arcuate nucleus 
A

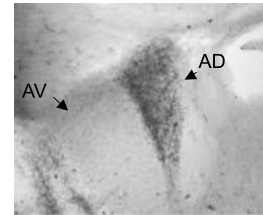

WT

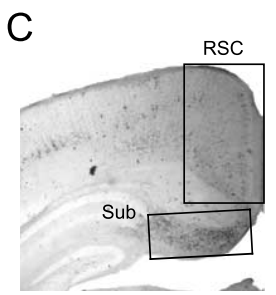

WT

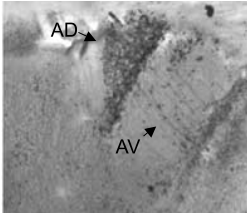

DKO

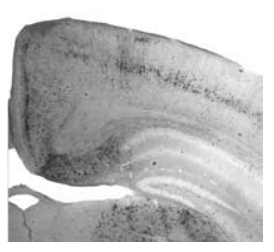

$B$

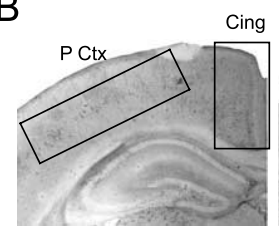

WT

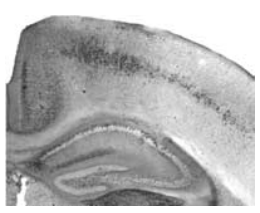

DKO

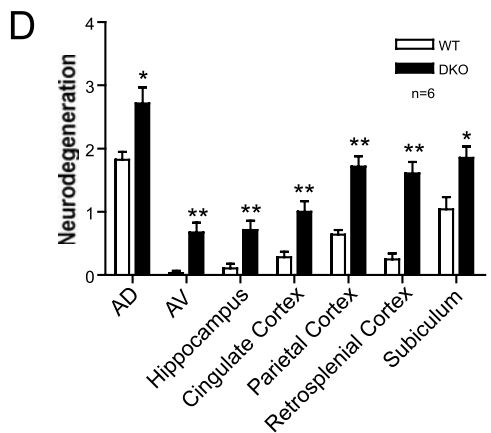

Figure 4. Neurodegeneration after administration of the GABAergic modulator phenobarbital is enhanced in the brains of neonatal DKO mice compared with WT mice. $A$, Representative sections depicting the median amount of silver deposition for each genotype in the anterodorsal (AD) and anteroventral (AV) thalamic nuclei of WT and DKO brains $24 \mathrm{~h}$ after administration of 70 $\mathrm{mg} / \mathrm{kg}$ phenobarbital. $\boldsymbol{B}$, Representative sections depicting the median amount of silver deposition for each genotype in the hippocampus, cingulate cortex (Cing), and parietal cortex (P (tx) of WT and DKO brains $24 \mathrm{~h}$ after administration of $70 \mathrm{mg} / \mathrm{kg}$ phenobarbital. C, Representative sections depicting the median amount of silver deposition for each genotype in the retrosplenial cortex (RSC) and subiculum (Sub) of WT and DKO brains $24 \mathrm{~h}$ after administration of $70 \mathrm{mg} / \mathrm{kg}$ phenobarbital. D, Quantitation of neurodegeneration in various brain regions of neonatal WT and DKO mice $24 \mathrm{~h}$ after administration of $70 \mathrm{mg} / \mathrm{kg}$ phenobarbital $\left({ }^{*} p<0.05\right.$ vs WT; ${ }^{* *} p<0.01$ vs WT; $n=6$ mice per genotype).

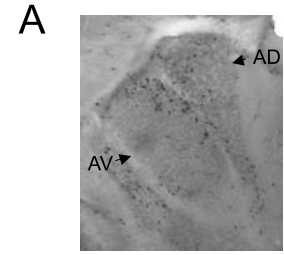

WT

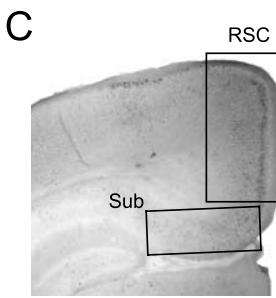

WT

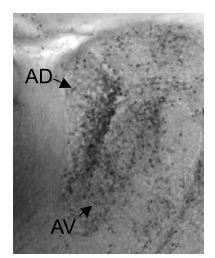

DKO

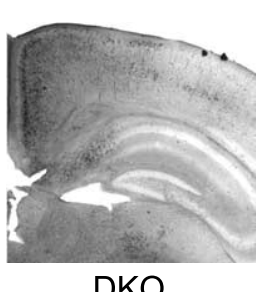

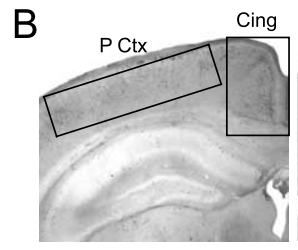

WT

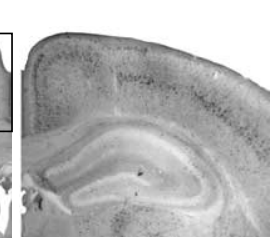

DKO

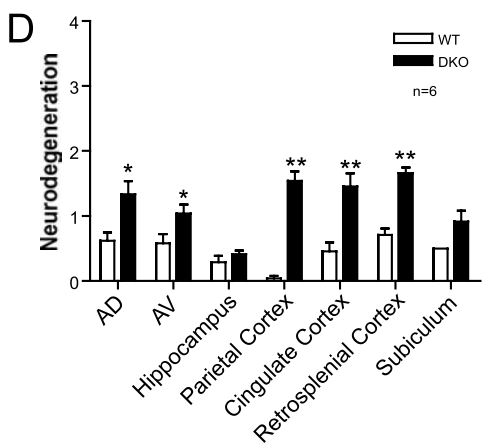

Figure 5. Neurodegeneration after administration of the NMDA receptor antagonist MK801 is enhanced in the brains of neonatal DKO mice compared with WT mice. $A$, Representative sections depicting the median amount of silver deposition for each genotype in the anterodorsal (AD) and anteroventral (AV) thalamic nuclei of WT and DKO brains $24 \mathrm{~h}$ after administration of three doses of $0.65 \mathrm{mg} / \mathrm{kg}$ MK801. B, Representative sections depicting the median amount of silver deposition for each genotype in the hippocampus, cingulate cortex (Cing), and parietal cortex (P Ctx) of WT and DKO brains $24 \mathrm{~h}$ after administration of three doses of $0.65 \mathrm{mg} / \mathrm{kg}$ MK801. C, Representative sections depicting the median amount of silver deposition for each genotype in the retro-

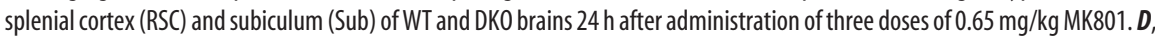
Quantitation of neurodegeneration in various brain regions of neonatal WT and DK0 mice $24 \mathrm{~h}$ after administration of three doses of $0.65 \mathrm{mg} / \mathrm{kg} \mathrm{MK801} \mathrm{(}{ }^{*} p<0.05$ vs WT; ${ }^{* *} p<0.01$ vs WT; $n=6$ mice per genotype). of WT and DKO mice after administration of $1.25 \mathrm{~g} / \mathrm{kg}$ monosodium glutamate. The degree of excitotoxic cell death did not differ between WT and DKO mice, as measured by either the number of degenerating cells in the arcuate nucleus (Fig. $7 A-C)$ or the size of the excitotoxic lesion (data not shown). Unlike physiological apoptotic cell death, excitotoxic cell death is not seen in the developing brain in the absence of monosodium glutamate administration (Perez et al., 1979). We assessed the degree of apoptotic neurodegeneration $24 \mathrm{~h}$ after $\mathrm{H} / \mathrm{I}$ by measuring caspase- 3 activity levels in hippocampi ipsilateral and contralateral to the ligated carotid artery. In this model, caspase-3 activation occurs in the hemisphere ipsilateral but not contralateral to carotid ligation. Caspase-3 activity was increased significantly after H/I (ipsilateral vs contralateral), but this increase did not differ between WT and DKO mice (Fig. 7D). It is unlikely that this result is caused by a ceiling effect, because longer durations of hypoxia-ischemia produce greater levels of caspase-3 activity in C57BL/6 mice than we show here (Zhu et al., 2005), and similar numbers of WT and DKO mice demonstrated low levels of caspase- 3 activity after $\mathrm{H} / \mathrm{I}$ (data not shown).

\section{Loss of calcium-stimulated ACs does not alter levels of trophic factors of apoptotic modulators}

Although we demonstrated previously that ethanol has no direct effect on calcium-stimulated AC activity (Maas and Muglia, unpublished results), it is possible that the enhanced neurodegeneration in DKO mice may result from a priori alterations in the levels of trophic factors or regulators of apoptosis in the brain caused by loss of the calcium-stimulated ACs. We examined the levels of BDNF in the brains of WT and DKO mice at various time points before and after ethanol administration and found no differences between genotypes or changes in BDNF induced by ethanol exposure. BDNF levels in the brains of untreated WT mice and WT mice 1 and $8 \mathrm{~h}$ after injection of $2.2 \mathrm{~g} / \mathrm{kg}$ ethanol were $19.7 \pm 1.4 \mathrm{pg} / \mathrm{mg}$ protein $(n=6), 22.3 \pm 3.3 \mathrm{pg} / \mathrm{mg}$ protein $(n=3)$, and $20.5 \pm 1.1 \mathrm{pg} / \mathrm{mg}$ protein $(n=3)$, respectively. BDNF levels in the brains of untreated DKO mice and DKO mice 1 and $8 \mathrm{~h}$ after injection of $2.2 \mathrm{~g} / \mathrm{kg}$ ethanol were $19.9 \pm 1.2 \mathrm{pg} / \mathrm{mg}$ protein $(n=6), 24.8 \pm$ $1.5 \mathrm{pg} / \mathrm{mg}$ protein $(n=3)$, and $17.2 \pm 0.69$ $\mathrm{pg} / \mathrm{mg}$ protein $(n=3)$, respectively. BDNF levels did not differ significantly between genotypes or after ethanol expo- 
sure (genotype, overall ANOVA, $F_{(1,28)}=$ $0.0278, p=0.87$; ethanol, overall ANOVA, $\left.F_{(4,28)}=1.583, p=0.21\right)$ We also examined the levels of phosphorylated and total CREB (cAMP response element-binding protein) and apoptotic regulators such as $\mathrm{Bcl}-2, \mathrm{Bcl}-$ $\mathrm{x}_{\mathrm{L}}$, and phosphorylated $\mathrm{BAD}$ (Bcl-2-associated death protein) in the brains of untreated WT and DKO mice and in the brains of WT and DKO mice at several times after ethanol injection by densitometric analysis of Western blots and found no differences in the levels of these proteins between genotypes or after ethanol administration (data not shown). Furthermore, there was no difference in the degree of naturally occurring cell death in the brains of WT and DKO mice (data not shown).

\section{Discussion}

Here, we demonstrate that $\mathrm{AC} 1$ and $\mathrm{AC} 8$ are expressed widely throughout the neonatal brain and that acute treatment of neonatal mice with ethanol or agents that mimic the antagonism of the NMDA receptor or potentiation of the $\mathrm{GABA}_{\mathrm{A}}$ receptor by ethanol leads to enhanced neurodegeneration in the brains of $\mathrm{AC} 1 \mathrm{KO}$, AC8 KO, and DKO mice compared with WT mice. Others have hypothesized that the loss of a single calcium-stimulated AC isoform can be compensated for by the remaining isoform (i.e., $\mathrm{ACl}$ in $\mathrm{AC} 8 \mathrm{KOs}$ and vice versa). This conclusion is supported by the demonstration that, although $\mathrm{AC} 1 \mathrm{KO}$ and $\mathrm{AC} 8 \mathrm{KO}$ mice do not display memory deficits or alterations in long-term potentiation in area CA1 of the hippocampus, DKO mice have deficits in both of these parameters (Wong et al., 1999). Our results indicate that this is not fully the case for neurodegeneration in the neonatal brain, because loss of a single calcium-stimulated AC isoform is sufficient to potentiate neurodegeneration after activity blockade to levels equivalent to those seen in DKO mice. It should be noted, however, that certain regions displayed levels of neurodegeneration in the $\mathrm{AC} 1 \mathrm{KO}$ or $\mathrm{AC} 8 \mathrm{KO}$ mice that were either intermediate between WT and DKO mice (e.g., subiculum after $2.2 \mathrm{~g} / \mathrm{kg}$ ethanol) or comparable with that seen in WT mice (parietal cortex after phenobarbital and cingulate cortex after MK801).

Ethanol treatment produced a dose-dependent increase in neurodegeneration in the brains of $\mathrm{WT}, \mathrm{AC} 1 \mathrm{KO}, \mathrm{AC} 8 \mathrm{KO}$, and DKO mice. Notably, the enhanced neurodegeneration after ethanol administration displayed by the AC KO mice may be subject to a ceiling effect, such that the absolute difference in neurodegeneration in the brains of WT and AC KO mice is smaller after $2.5 \mathrm{~g} / \mathrm{kg}$ ethanol than it is after $2.2 \mathrm{~g} / \mathrm{kg}$ ethanol. Thus, the calcium-stimulated ACs play an important role in modulating ethanol-induced neurodegeneration within a specific range of ethanol exposure.

Ethanol-induced neurodegeneration in the brains of neonatal mice occurs by Bax-dependent activation of caspase- 3 and subsequent apoptotic cell death (Ikonomidou et al., 2000; Young et
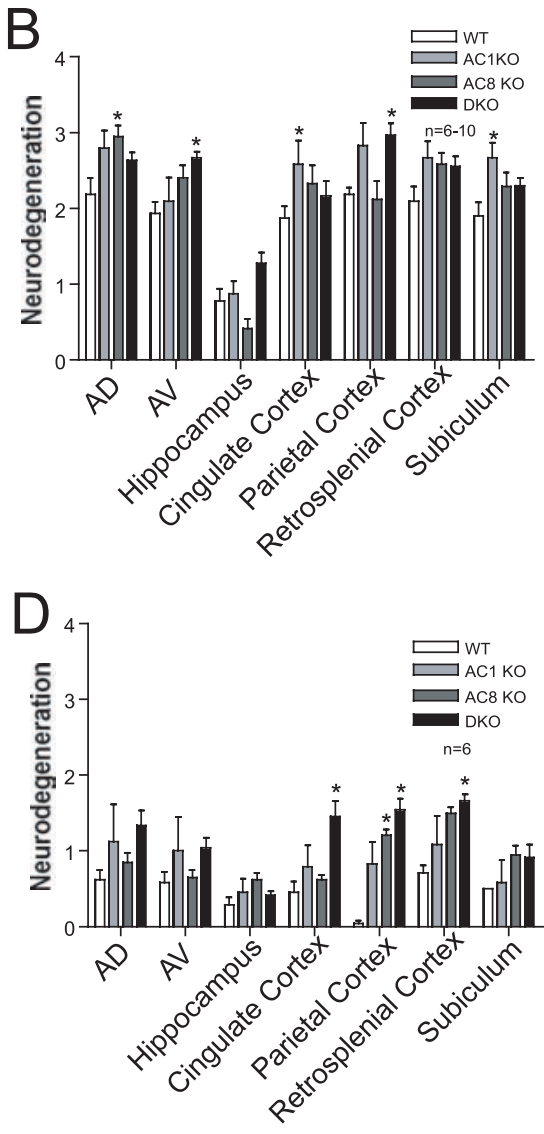

Figure 6. Loss of a single calcium-stimulated $A C$ is oform is sufficient to potentiate neurodegeneration after administration of . various brain regions of neonatal WT, AC1 K0, AC8 K0, and DKO mice $24 \mathrm{~h}$ after administration of $70 \mathrm{mg} / \mathrm{kg}$ phenobarbital $\left({ }^{*} p<\right.$ 0.05 vs WT; $n=6-7$ mice per genotype). $\boldsymbol{D}$, Quantitation of neurodegeneration in various brain regions of neonatal WT, AC1 KO, AC8 K0, and DKO mice $24 \mathrm{~h}$ after administration of three doses of $0.65 \mathrm{mg} / \mathrm{kg} \mathrm{MK801}\left({ }^{*} p<0.05 \mathrm{vs} \mathrm{WT} ; n=6\right.$ mice per genotype).

al., 2003; Carloni et al., 2004). Furthermore, Bax-deficient mice do not display ethanol-induced caspase-3 activation or neurodegeneration (Young et al., 2003). Consequently, we assessed the degree of caspase-3 activation after ethanol administration and found that cleaved caspase- 3 levels were significantly increased in the brains of DKO mice compared with WT mice after administration of $2.2 \mathrm{~g} / \mathrm{kg}$ ethanol. These results provide additional support for our conclusion that DKO mice have enhanced sensitivity to ethanolinduced neurodegeneration and validate the use of quantitation of silver deposition as a tool to detect differences between genotypes in the degree of ethanol-induced neurodegeneration.

One of the effects of ethanol on neurons is inhibition of the NMDA receptor (Dildy and Leslie, 1989; Lovinger et al., 1989, 1990), and administration of MK801, an NMDA receptor antagonist, results in neurodegeneration in the neonatal brain (Ikonomidou et al., 1999, 2000). Activation of the NMDA receptor has been postulated to result in activation of the calcium-stimulated ACs, because both direct application of NMDA to hippocampal slices and electrophysiological stimulation that results in NMDA receptor activation result in calcium-dependent cAMP elevation (Chetkovich et al., 1991; Chetkovich and Sweatt, 1993). Furthermore, DKO mice display deficits in NMDA-dependent phenomena such as fear conditioning and long-term potentiation (Wong et al., 1999). Consequently, we hypothesized that the enhanced 
A

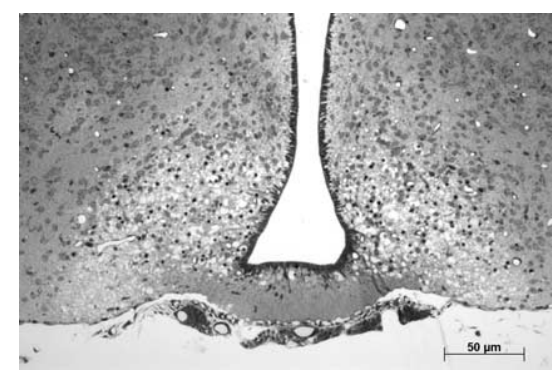

B

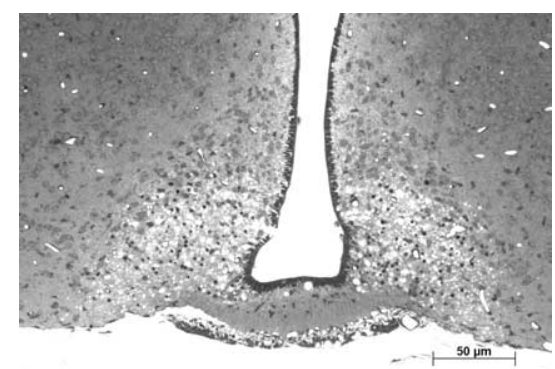

C

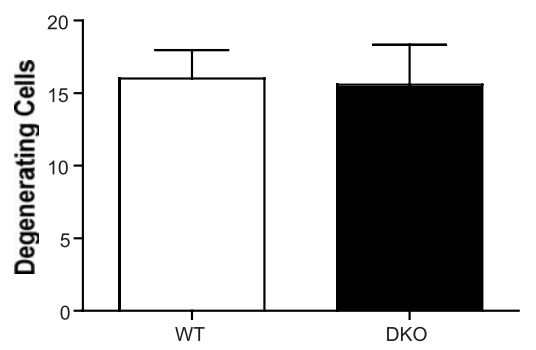

D

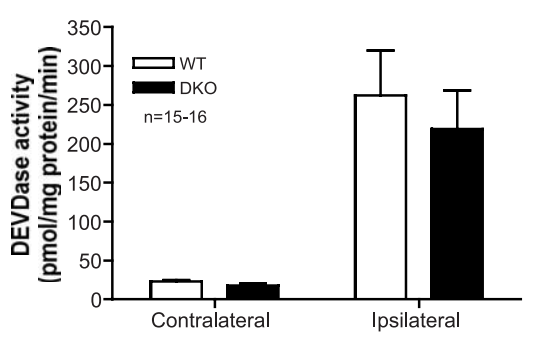

Figure 7. Loss of calcium-stimulated ACs does not sensitize neurons to excitotoxic or hypoxic/ischemic death. $\boldsymbol{A}$, Representative section of excitotoxic cell death in brain of neonatal WT mouse after administration of $1.25 \mathrm{~g} / \mathrm{kg}$ monosodium glutamate. $\boldsymbol{B}$, Representative section of excitotoxic cell death in brain of neonatal DKO mouse after administration of $1.25 \mathrm{~g} / \mathrm{kg}$ monosodium glutamate. C, Quantitation of excitotoxic cell death in arcuate nucleus of neonatal WT and DKO mice ( $n=7$ mice per genotype). $D$, Caspase-3 activity (as assessed by cleavage of substrate DEVD) in lysates of hippocampi ipsilateral and contralateral to the site of carotid artery ligation $24 \mathrm{~h}$ after hypoxia/ischemia.

neurodegeneration observed in the brains of DKO mice might be caused by the inhibition of the NMDA receptor by ethanol. Consistent with this, administration of MK801 resulted in increased neurodegeneration in the brains of DKO mice compared with WT mice, providing support for the idea that calcium influx through the NMDA receptor leads to the activation of AC1 and AC8.

In addition to its effects on the NMDA receptor, ethanol also potentiates the function of the inhibitory $\mathrm{GABA}_{\mathrm{A}}$ receptor (Mehta and Ticku, 1988; Harris et al., 1995; Wallner et al., 2003). Surprisingly, DKO mice also exhibited increased neurodegeneration compared with WT mice after administration of phenobarbital, a GABAergic modulator. Thus, the enhanced neurodegeneration seen in the brains of DKO mice after ethanol exposure is not simply caused by the inhibition of the NMDA receptor by ethanol. Furthermore, these results indicate that the role of the calcium-stimulated ACs is not limited to modulation of NMDAdependent signaling; rather, they modulate neurodegeneration induced by several different agents that produce reduced neuronal activity through different mechanisms. However, it should be noted that the neurodegenerative effects of phenobarbital could be attributable to decreased NMDA receptor activity, because administration of a GABAergic modulator could result in decreased glutamate release by the presynaptic neuron or decreased depolarization of the postsynaptic neuron, both of which could result in decreased NMDA receptor activation.

Importantly, the modulation of neuronal death by $\mathrm{AC} 1$ and AC8 are specific for agents that induce activity blockade, because the levels of naturally occurring cell death and neuronal death after hypoxia/ischemia or excitoxicity were unaltered in the brains of neonatal DKO mice. Furthermore, there are no changes in the levels of several trophic factors and several proteins that regulate apoptosis in the brains of $\mathrm{DKO}$ mice. Thus, it is likely that deletion of the calcium-stimulated ACs does not result in a priori changes in neuronal function that enhance neuronal death in the neonatal brain. Although the exact mechanism leading to neurodegeneration induced by activity blockade remains to be determined, clearly the calcium-stimulated ACs are important modulators of this process. These results are consistent with data from our group and others that demonstrate that altering the activity of several components of the cAMP signaling pathway, including $G_{s \alpha}$, calcium-stimulated ACs, and PKA, alters sensitivity to ethanol in adult mice (Moore et al., 1998; Thiele et al., 2000; Wand et al., 2001) (Maas and Muglia, unpublished results). The role of PKA activation differences between WT and DKO mice in ethanol-induced neurodegeneration is currently the subject of ongoing investigation in our laboratory.

It should be noted that the enhanced sensitivity of neonatal DKO mice to agents that mimic components of the actions of ethanol differs from what is seen in adult mice. Whereas adult DKO mice demonstrate enhanced ethanol-induced sedation compared with WT mice, they do not demonstrate enhanced sensitivity to either an NMDA antagonist or a GABAergic modulator (Maas and Muglia, unpublished results). Thus, it is possible that the mechanisms leading to the activation of the calcium-stimulated ACs change during the course of development, and such a possibility merits additional investigation. Whereas some of the functions of the calcium-stimulated ACs in the adult brain have been established, the roles played by $\mathrm{AC} 1$ and $\mathrm{AC} 8$ in the developing brain have not been addressed. Calcium-stimulated AC activity is present at $\mathrm{P} 7$ and increases significantly in the brain throughout development (Villacres et al., 1995), although it has not been demonstrated if this is caused by increasing levels of AC1 and/or AC8. Here we show that both AC1 and AC8 are expressed at significant levels throughout the brain 1 week after birth. Importantly, both $\mathrm{AC} 1$ and $\mathrm{AC} 8$ are expressed in each of the regions we examined for neurodegeneration, including thalamus, cortex, and hippocampus. Interestingly, AC1 expression is more widespread at P7 than it is in the adult brain (Schaefer et al., 2000) and thus may modulate neuronal function in a greater number of brain regions in the neonatal mouse than in the adult mouse.

Although there is a clear correlation between maternal ethanol consumption and the occurrence of fetal alcohol spectrum disorders, there is large variation in the dose-response relationship between the extent of maternal ethanol consumption and the severity of resulting sequelas (Ernhart, 1991; Abel, 1995). One factor that affects the extent of cognitive sequelas is fetal genotype, as shown by twin studies (Streissguth and Dehaene, 1993). However, the nature of these modifying genetic loci is unclear. Because the genetic deletion of the calcium-stimulated ACs potentiates ethanol-induced neurodegeneration, they represent potential genetic loci, the relative expression of which could modify fetal sensitivity to maternal ethanol exposure and the subsequent development of cognitive sequelas. Furthermore, although it 
would seem that administration of ethanol to neonatal mice would not be comparable with the prenatal exposure that occurs in FAS, there are large variations in brain development across species, and the period of brain development that begins in the third trimester of human gestation is comparable with the period that takes place during the first postnatal week of rodent development (Dobbing and Sands, 1979). Consequently, the studies detailed here may be quite relevant to individual susceptibility to FAS.

\section{References}

Abel EL (1995) An update on incidence of FAS: FAS is not an equal opportunity birth defect. Neurotoxicol Teratol 17:437-443.

Boatright KM, Salvesen GS (2003) Mechanisms of caspase activation. Curr Opin Cell Biol 15:725-731.

Cali JJ, Zwaagstra JC, Mons N, Cooper DM, Krupinski J (1994) Type VIII adenylyl cyclase. $\mathrm{A} \mathrm{Ca}^{2+} /$ calmodulin-stimulated enzyme expressed in discrete regions of rat brain. J Biol Chem 269:12190-12195.

Carloni S, Mazzoni E, Balduini W (2004) Caspase-3 and calpain activities after acute and repeated ethanol administration during the rat brain growth spurt. J Neurochem 89:197-203.

Chetkovich DM, Sweatt JD (1993) nMDA receptor activation increases cyclic AMP in area CA1 of the hippocampus via calcium/calmodulin stimulation of adenylyl cyclase. J Neurochem 61:1933-1942.

Chetkovich DM, Gray R, Johnston D, Sweatt JD (1991) N-methyl-Daspartate receptor activation increases cAMP levels and voltage-gated $\mathrm{Ca}^{2+}$ channel activity in area CA1 of hippocampus. Proc Natl Acad Sci USA 88:6467-6471.

DeOlmos JS, Ingram WR (1971) An improved cupric-silver method for impregnation of axonal and terminal degeneration. Brain Res 33:523-529.

Dildy JE, Leslie SW (1989) Ethanol inhibits NMDA-induced increases in free intracellular $\mathrm{Ca}^{2+}$ in dissociated brain cells. Brain Res 499:383-387.

D’Mello SR, Galli C, Ciotti T, Calissano P (1993) Induction of apoptosis in cerebellar granule neurons by low potassium: inhibition of death by insulin-like growth factor I and cAMP. Proc Natl Acad Sci USA 90:10989-10993.

Dobbing J, Sands J (1979) Comparative aspects of the brain growth spurt. Early Hum Dev 3:79-83.

Ernhart CB (1991) Clinical correlations between ethanol intake and fetal alcohol syndrome. Recent Dev Alcohol 9:127-150.

Franklin JL, Johnson Jr EM (1992) Suppression of programmed neuronal death by sustained elevation of cytoplasmic calcium. Trends Neurosci 15:501-508.

Han BH, D'Costa A, Back SA, Parsadanian M, Patel S, Shah AR, Gidday JM, Srinivasan A, Deshmukh M, Holtzman DM (2000) BDNF blocks caspase-3 activation in neonatal hypoxia-ischemia. Neurobiol Dis $7: 38-53$.

Hanson Jr MG, Shen S, Wiemelt AP, McMorris FA, Barres BA (1998) Cyclic AMP elevation is sufficient to promote the survival of spinal motor neurons in vitro. J Neurosci 18:7361-7371.

Harris RA, Proctor WR, McQuilkin SJ, Klein RL, Mascia MP, Whatley V, Whiting PJ, Dunwiddie TV (1995) Ethanol increases GABA A $_{\mathrm{A}}$ responses in cells stably transfected with receptor subunits. Alcohol Clin Exp Res 19:226-232.

Ikonomidou C, Bosch F, Miksa M, Bittigau P, Vockler J, Dikranian K, Tenkova TI, Stefovska V, Turski L, Olney JW (1999) Blockade of NMDA receptors and apoptotic neurodegeneration in the developing brain. Science 283:70-74.

Ikonomidou C, Bittigau P, Ishimaru MJ, Wozniak DF, Koch C, Genz K, Price MT, Stefovska V, Horster F, Tenkova T, Dikranian K, Olney JW (2000) Ethanol-induced apoptotic neurodegeneration and fetal alcohol syndrome. Science 287:1056-1060.

Jones KL, Smith DW (1973) Recognition of the fetal alcohol syndrome in early infancy. Lancet 2:999-1001.

Lara J, Kusano K, House S, Gainer H (2003) Interactions of cyclic adenosine monophosphate, brain-derived neurotrophic factor, and glial cell linederived neurotrophic factor treatment on the survival and growth of postnatal mesencephalic dopamine neurons in vitro. Exp Neurol 180:32-45.

Levine S (1960) Anoxic-ischemic encephalopathy in rats. Am J Pathol 36:1-17.
Lovinger DM, White G, Weight FF (1989) Ethanol inhibits NMDAactivated ion current in hippocampal neurons. Science 243:1721-1724.

Lovinger DM, White G, Weight FF (1990) NMDA receptor-mediated synaptic excitation selectively inhibited by ethanol in hippocampal slice from adult rat. J Neurosci 10:1372-1379.

Mehta AK, Ticku MK (1988) Ethanol potentiation of GABAergic transmission in cultured spinal cord neurons involves gamma-aminobutyric acidA-gated chloride channels. J Pharmacol Exp Ther 246:558-564.

Mennerick S, Zorumski CF (2000) Neural activity and survival in the developing nervous system. Mol Neurobiol 22:41-54.

Meyer-Franke A, Kaplan MR, Pfrieger FW, Barres BA (1995) Characterization of the signaling interactions that promote the survival and growth of developing retinal ganglion cells in culture. Neuron 15:805-819.

Meyer-Franke A, Wilkinson GA, Kruttgen A, Hu M, Munro E, Hanson Jr MG, Reichardt LF, Barres BA (1998) Depolarization and cAMP elevation rapidly recruit TrkB to the plasma membrane of CNS neurons. Neuron 21:681-693.

Moore MS, DeZazzo J, Luk AY, Tully T, Singh CM, Heberlein U (1998) Ethanol intoxication in Drosophila: genetic and pharmacological evidence for regulation by the cAMP signaling pathway. Cell 93:997-1007.

Moulder KL, Fu T, Melbostad H, Cormier RJ, Isenberg KE, Zorumski CF, Mennerick S (2002) Ethanol-induced death of postnatal hippocampal neurons. Neurobiol Dis 10:396-409.

Muglia LM, Schaefer ML, Vogt SK, Gurtner G, Imamura A, Muglia LJ (1999) The 5'-flanking region of the mouse adenylyl cyclase type VIII gene imparts tissue-specific expression in transgenic mice. J Neurosci 19:2051-2058.

Olney JW (1971) Glutamate-induced neuronal necrosis in the infant mouse hypothalamus. An electron microscopic study. J Neuropathol Exp Neurol 30:75-90.

Olney JW, Tenkova T, Dikranian K, Muglia LJ, Jermakowicz WJ, D’Sa C, Roth KA (2002) Ethanol-induced caspase-3 activation in the in vivo developing mouse brain. Neurobiol Dis 9:205-219.

Perez VJ, Olney JW, Martin JF, Cannon WO (1979) Minimal tissue concentrations of glutamate required to produce necrosis of hypothalamic neurons in newborn mice. Biol Neonate 35:17-22.

Reiriz J, Holm PC, Alberch J, Arenas E (2002) BMP-2 and cAMP elevation confer locus coeruleus neurons responsiveness to multiple neurotrophic factors. J Neurobiol 50:291-304.

Sampson PD, Streissguth AP, Bookstein FL, Little RE, Clarren SK, Dehaene P, Hanson JW, Graham Jr JM (1997) Incidence of fetal alcohol syndrome and prevalence of alcohol-related neurodevelopmental disorder. Teratology 56:317-326.

Schaefer ML, Wong ST, Wozniak DF, Muglia LM, Liauw JA, Zhuo M, Nardi A, Hartman RE, Vogt SK, Luedke CE, Storm DR, Muglia LJ (2000) Altered stress-induced anxiety in adenylyl cyclase type VIII-deficient mice. J Neurosci 20:4809-4820.

Streissguth AP, Dehaene P (1993) Fetal alcohol syndrome in twins of alcoholic mothers: concordance of diagnosis and IQ. Am J Med Genet 47:857-861.

Streissguth AP, Aase JM, Clarren SK, Randels SP, LaDue RA, Smith DF (1991) Fetal alcohol syndrome in adolescents and adults. JAMA 265:1961-1967.

Tang WJ, Krupinski J, Gilman AG (1991) Expression and characterization of calmodulin-activated (type I) adenylylcyclase. J Biol Chem 266:8595-8603.

Thiele TE, Marsh DJ, Ste Marie L, Bernstein IL, Palmiter RD (1998) Ethanol consumption and resistance are inversely related to neuropeptide $Y$ levels. Nature 396:366-369.

Thiele TE, Willis B, Stadler J, Reynolds JG, Bernstein IL, McKnight GS (2000) High ethanol consumption and low sensitivity to ethanol-induced sedation in protein kinase A-mutant mice. J Neurosci 20:RC75(1-6).

Verhage M, Maia AS, Plomp JJ, Brussaard AB, Heeroma JH, Vermeer H, Toonen RF, Hammer RE, van den Berg TK, Missler M, Geuze HJ, Sudhof TC (2000) Synaptic assembly of the brain in the absence of neurotransmitter secretion. Science 287:864-869.

Villacres EC, Wu Z, Hua W, Nielsen MD, Watters JJ, Yan C, Beavo J, Storm DR (1995) Developmentally expressed $\mathrm{Ca}^{(2+)}$-sensitive adenylyl cyclase activity is disrupted in the brains of type I adenylyl cyclase mutant mice. J Biol Chem 270:14352-14357.

Wallner M, Hanchar HJ, Olsen RW (2003) Ethanol enhances alpha 4 beta 3 
delta and alpha 6 beta 3 delta gamma-aminobutyric acid type A receptors at low concentrations known to affect humans. Proc Natl Acad Sci USA 100:15218-15223.

Wand G, Levine M, Zweifel L, Schwindinger W, Abel T (2001) The cAMPprotein kinase A signal transduction pathway modulates ethanol consumption and sedative effects of ethanol. J Neurosci 21:5297-5303.

Wong ST, Athos J, Figueroa XA, Pineda VV, Schaefer ML, Chavkin CC, Muglia LJ, Storm DR (1999) Calcium-stimulated adenylyl cyclase activity is critical for hippocampus-dependent long-term memory and late phase LTP. Neuron 23:787-798.

Wozniak DF, Hartman RE, Boyle MP, Vogt SK, Brooks AR, Tenkova T, Young C, Olney JW, Muglia LJ (2004) Apoptotic neurodegeneration induced by ethanol in neonatal mice is associated with profound learning/ memory deficits in juveniles followed by progressive functional recovery in adults. Neurobiol Dis 17:403-414.
Wu ZL, Thomas SA, Villacres EC, Xia Z, Simmons ML, Chavkin C, Palmiter RD, Storm DR (1995) Altered behavior and long-term potentiation in type I adenylyl cyclase mutant mice. Proc Natl Acad Sci USA 92:220-224.

Xia ZG, Refsdal CD, Merchant KM, Dorsa DM, Storm DR (1991) Distribution of mRNA for the calmodulin-sensitive adenylate cyclase in rat brain: expression in areas associated with learning and memory. Neuron 6:431-443.

Young C, Klocke BJ, Tenkova T, Choi J, Labruyere J, Qin YQ, Holtzman DM, Roth KA, Olney JW (2003) Ethanol-induced neuronal apoptosis in vivo requires $\mathrm{BAX}$ in the developing mouse brain. Cell Death Differ 10:1148-1155.

Zhu C, Wang X, Xu F, Bahr BA, Shibata M, Uchiyama Y, Hagberg H, Blomgren K (2005) The influence of age on apoptotic and other mechanisms of cell death after cerebral hypoxia-ischemia. Cell Death Differ $12: 162-176$. 